Spectrum of the Corona.-- Several additional faint lines have been found in the spectrum of the corona by the Rev. A. L. Cortie, S.J., on photographs taken at Hernösand, Sweden, during the total eclipse of the sun on August 2I, Igr4 (Monthly Notices, R.A.S., vol. Ixxviii., p. 665). In the region extending from 6615.7 to $4780 \mathrm{~A}$ thirty-six lines were measured, of which twenty-four do not appear in any previous records. The wave-length of the prominent red line which was first noted at this eclipse is given as $6373 \cdot 3$.

\section{AGUE IN ENGLAND.'}

I N 1917 there were reported I36 military, I9 naval, and 23 civilian cases of malaria contracted in England, i.e. in people who had not been out of the country. Fifty-three of the milicury cases occurred in the Sheerness and Sheppey areas, and fiftythree in the Sandwich area. As these cases, all of simple tertian malaria, began to arise, the attention of medical ofiicers of health and other medical men was directed to the matter by the Local Government Board, and the problem of the possible danger to the civilian population of the influx of malaria-infected soldiers from abroad was considered. This report records the action that was taken to deal with the situation, and that it is proposed to take should the cases assume any serious magnitude in 1918.

It would appear from the information collected that the evidence is fairly clear that malaria had not completely died out in this country, as was generally thought to be the case, perhaps, with very rare exceptions; but, on the other hand, the cases in 1917 were a new phenomenon, and there can be no reasonable doubt that the cause of these cases was the new supply of infection, viz. soldiers from overseas.

Whether the whole official action as recommended in this report has not been "much ado about nothing" it is, perhaps, a little premature to say, but it was noticeable in some areas in I9I7 that, aithough there were numerous infected soldiers, the number of indigenous cases that occurred amongst the surrounding non-infected population was in some instarices a solitary one, giving ground for the hope that in 1918 the number of cases might still be small, and not such as to be dignified by the term "epidemic." Should, however, an epidemic occur, the problem of the best line of action has to be faced. We agree with the view expressed in the introduction of the report, that "comprehensive anti-mosquito work is impracticable," and believe that the use of quinine would make such work unnecessary. It is true that we cannot by the use of quinine "disinfect," i.e. destroy all the parasites in a person's system, but we can readily do so partiallyi.e. we can, in these cases of simple tertian malaria, by adequate doses of quinine, render the blood completely free from all parasites, sexual as well as asexual, for long periods (months), so that, as regards Anophelines, such cases are non-infective, and, of course, equally so are the Anophelines. We believe that civilians would readily acquiesce in such treatment, all the more when they appreciated the fact that thereby they were kept free from fever and got a better chance of ultimate recovery. The report contains a special article on the microscopic diagnosis of malaria, but medical men can be taught this only by practical work in a laboratory.

The map showing the distribution of Anophelines in England, prepared by the British Museum authorities, contains some omissions which might have been filled had inquiries been made in likely quarters.

1 Reports to the Local Government Board on Public Health and Medical Subjects. (New Serios No. Ir9.) Reports and Papers on Malaria contracted
in England in I9x7. (London: H.M.S.O., rgr.8) Price 4 s. net. NO. 2562 , VOL. TO2]

\section{NATURAL INDIGO MANUFACTURE.}

IN "Indigo Publication No. 3 ," issued by the Agritural Research Institute at Pusa, Mr. W. A. Davis, indigo research chemist to the Government of India, directs attention to a method of avoiding the loss of dyestuff which frequently occurs in the manufacture of natural indigo, due to finely divided particles of the dye remaining suspended in the large volume of extraction water (seet water) which is run off after "beating" is finished and the indigo has apparently settled. In indigo factories where working conditions are good the water running from the filtering tables is of pale sherry colour, but where fermentation in the vats is unsatisfactory, or the quality of the indigo plants grown in the neighbourhood is poor, the water finally run off may be distinctly green in colour, due to finely divided, susperded indigo. Of the two kinds of indigo plant grown in India the loss from this cause is greater with the Sumatrana than with the Java variety, as the former requires a large volume of water for extraction.

The settling agent which Mr. Davis suggests for general use is Dhak gum, a ruby-coloured gum produced by the Dhak or palas tree (Butea frondosa). This material has occasionally been employed for the purpose in the United Provinces, and was first brought to Mr. Davis's attention by Mr. Kenyon, of Sultanpur. Trials of the gum as a settling agent were made at a number of indigo factories in Bihar last season, and gave excellent results, the yield from Sumatrana plant at one factory being increased by $37 \frac{1}{2}$ per cent., and from Java plant at another factory by 16 per cent., these being average increases throughout the wrorking period. The results of analyses of indigo made at various factories, with and without the use of Dhak gum, showed that the addition of this material to the settling-vat had no appreciable effect on the quality of the dyestuff produced. Further, it was at the factories where the fermentation conditions were unfavourable, or the quality of the plant used was poor, that the use of Dhal gum gave the best results, both in facilitating settling and filtration and in increasing the yield of dyestuff.

\section{DYES AND THE DEVELOPMENT OF BRITISH CHEMICAL INDUSTRY.}

THE Association of British Chemical Manufacturers sent to the President of the Board of

Trade on November $I$ the sollowing memorandum, setting forth the views of the executive council of the association on the present situation in that section of chemical industry directly concerned with the production of dyes:-

(I) A wider and more comprehensive scheme of a completely national nature is immediately requisite if a supply of the colours, in variety and quantity essential to the conduct of our great textile industry, is to be forthcoming within a reasonable period of years, and especially with a view to the early elimination of all dependence on overseas supplies.

(2) The fundamental error which resulted in an inadequate policy in British dye production is the failure on the part of the originators of that policy to recognise the fact that the manufacture of dyes is not, by itself, an industry apart; but is precisely an integral part of, and is dependent upon, the operations covered by the chemical manufacturing industry as a wholei.e. the manufacturer of heavy chemicals, of fine chemicals, of tar products, and of explosives have each and all separate functions to perform in developing a successful dye-producing industry in this country. 